\title{
A new $12 \%$ chromium steel strengthened by Z-phase precipitates
}

\begin{abstract}
In order to increase the corrosion resistance and simultaneously maintain the creep resistance of $9-12 \% \mathrm{Cr}$ steels at $650^{\circ} \mathrm{C}$, a new alloy design concept was proposed, using thermodynamically stable Z-phase $(\mathrm{CrTaN})$ precipitates to strengthen the steel. A new trial Zphase strengthened $12 \% \mathrm{Cr}$ steel was produced and creep tested. The steel exhibited good long-term creep resistance. Dense nano-sized Z-phase precipitates were formed at the early stage, and coarsened slowly. They remained small after more than 10,000 hours.
\end{abstract}

Key words: martensitic steels, creep, three-dimensional atom probe, transmission electron microscopy,

Martensitic $9-12 \% \mathrm{Cr}$ steels offer an optimal combination of the critical properties, i.e. creep strength, corrosion resistance, thermal conductivity and thermal expansion, at a relatively low cost. Therefore, they are by far the most used material for steam pipes and turbine components in steam power plants [1]. The thermal efficiency of these plants is limited by the maximum allowed steam temperature and pressure, which in turn are determined by the longterm creep and corrosion resistance of economically viable materials. Although austenitic steels have better creep and corrosion resistance, the superior thermal properties of $9-12 \% \mathrm{Cr}$ steels (high thermal conductivity and low thermal expansion) make them better suited for future power plants. For these plants thermo-flexibility is an essential requirement to accommodate the fluctuating nature of many of the major renewable sources of energy, such as wind and solar power. The cost of $9-12 \% \mathrm{Cr}$ steels is also substantially lower than austenitic steels, which is of great importance for the economy of introducing improved 
materials in large quantities - a turbine rotor forging or a turbine house casting may both weigh 50 tonnes, and steam pipes for a $1 \mathrm{GW}$ power plant weigh several hundred tonnes.

Today's best martensitic $9-12 \% \mathrm{Cr}$ steels can be used at $\sim 600^{\circ} \mathrm{C} / 300$ bar. For these steels the most important strengthening mechanism is precipitation hardening [2]. The size and number density of precipitates at the initial stage, as well as their stability against coarsening during exposure to high temperatures, play a vital role in creep resistance. For conventional $9-12 \%$ Cr steels, the carbide $\mathrm{M}_{23} \mathrm{C}_{6}(\mathrm{M}=\mathrm{Fe}, \mathrm{Cr}, \mathrm{Mo})$, the nitride $\mathrm{MN}(\mathrm{M}=\mathrm{V}, \mathrm{Nb})$, and the intermetallic Laves phase $\mathrm{Fe}_{2} \mathrm{M}(\mathrm{M}=\mathrm{Mo}, \mathrm{W})$ are the major strengthening precipitate families $[2,3]$.

The best $9-12 \% \mathrm{Cr}$ steels contain $9 \% \mathrm{Cr}$, which is too low in terms of corrosion resistance at $650^{\circ} \mathrm{C}$. It is well established that at high temperatures the corrosion resistance of a steel depends on its $\mathrm{Cr}$ content: the higher the $\mathrm{Cr}$ content, the better the corrosion resistance [4]. At $650^{\circ} \mathrm{C}, 9 \% \mathrm{Cr}$ steels oxidized more than 3 times quicker than $12 \% \mathrm{Cr}$ steels [5]. Therefore, there have been recent trials aiming at improving corrosion properties by increasing the $\mathrm{Cr}$ content (11-12\% vs. 9\%). Although the alloys showed better creep resistance at $650^{\circ} \mathrm{C}$ up to $\sim 10,000$ hours, they then suffered a dramatic loss of creep strength [6].

This breakdown is mainly due to the precipitation of the complex nitride known as Z-phase $((\mathrm{Cr}, \mathrm{Fe})(\mathrm{Nb}, \mathrm{V}) \mathrm{N})$ during creep. Z-phase is thermodynamically more stable than metal nitrides $(\mathrm{MN})$ at $600-650^{\circ} \mathrm{C}$ [7]. However, the nucleation of Z-phase is difficult. Once formed, a small number of nuclei grow very rapidly by consuming many small MN precipitates and finally form few and large particles that give very little contribution to creep strength $[7,8]$. A $\mathrm{Cr}$ 
content above $10.5 \%$ strongly accelerates Z-phase formation. In contrast, steels with $9 \% \mathrm{Cr}$ or below are largely unaffected by the Z-phase precipitation up to 100,000 hours at $600-650^{\circ} \mathrm{C}$ [9].

Danielsen and Hald proposed a new alloy design concept that makes use of Z-phase as strengthening dispersion instead of $\mathrm{MN}$ for $12 \% \mathrm{Cr}$ martensitic steels [9]. Good corrosion resistance is guaranteed by the high $\mathrm{Cr}$ content $(12 \%$ vs. $9 \%)$, which is also a necessary prerequisite for a rapid Z-phase formation [10]. Good creep resistance would be expected, if densely distributed fine Z-phase precipitates can be formed during heat treatment and if they coarsen slowly during service. In this study we prepared a trial Z-phase strengthened steel, and performed long-term creep testing and detailed microstructure analyses. We show that Zphase strengthening is feasible in $12 \% \mathrm{Cr}$ steels.

A low-carbon (50 wt. ppm) CrTaN-strengthened trial steel was prepared. The carbon content was carefully controlled in order to isolate the strengthening effect of Z-phase, without interference from carbides. Its chemical composition is presented in Table 1. The trial steel was produced in $80 \mathrm{~kg}$ ingots by vacuum induction melting. The ingots were hot rolled into $20 \mathrm{~mm}$ thick plates, austenitized at $1150^{\circ} \mathrm{C}$ for 1 hour, and then cooled in air to the room temperature. Materials with two heat treatment conditions, either tempered at $650^{\circ} \mathrm{C}$ for 24 hours or at $720^{\circ} \mathrm{C}$ for 6 hours, then underwent creep testing at $650^{\circ} \mathrm{C}$ under a constant load, using specimens of $8 \mathrm{~mm}$ in gauge diameter and $50 \mathrm{~mm}$ in gauge length. As quenched material that had been aged at $650^{\circ} \mathrm{C}$ for 24,1005 , and 10,000 hours were used for microstructural investigation. Z-phase precipitates were studied by using atom probe tomography (APT) and transmission electron microscopy (TEM). Needle-shaped specimens 
for APT characterization were prepared using a two-step electropolishing procedure [11]. The final radius of the specimen tip was less than $50 \mathrm{~nm}$. APT analysis was performed in an Imago LEAP 3000X HR local electrode atom probe instrument. During analysis the specimen was held at a temperature range of 55-60 K. To avoid premature specimen failure pulsed laser mode was used, with a laser energy of $0.3 \mathrm{~nJ}$ [12]. A pulse frequency of $200 \mathrm{kHz}$ was used. The acquired data were further analysed by using the IVAS 3.4 .1 software developed by Imago. TEM specimens were prepared by using an electropolishing method in $10 \%$ perchloric acid in methanol at $-30^{\circ} \mathrm{C}$. A Titan 80-300 TEM (300 kV) equipped with an energy dispersive X-ray spectrometry (EDX) system was used to analyse nano-sized Z-phase precipitates. The high angle annular dark field (HAADF) detector was used for imaging, since it yields good contrast between the steel matrix and precipitates, which contain heavy elements such as Ta and $\mathrm{W}$.

Figure 1 shows the creep strength versus rupture time curve at $650^{\circ} \mathrm{C}$ for the $\mathrm{CrTaN}$ strengthened trial steel in comparison with the benchmarks ASTM type P91 (9\% Cr-1\% Mo$0.2 \% \mathrm{~V}-0.05 \% \mathrm{Nb})$ and $\mathrm{P} 92(9 \% \mathrm{Cr}-0.5 \% \mathrm{Mo}-1.8 \% \mathrm{~W}-0.2 \% \mathrm{~V}-0.05 \% \mathrm{Nb})$, two of the most widely used 9-12\% Cr steels today. P91 and P92 are strengthened mainly by dispersion of $(\mathrm{V}, \mathrm{Nb})(\mathrm{C}, \mathrm{N})$ and $(\mathrm{Cr}, \mathrm{Fe})_{23} \mathrm{C}_{6}$ nano-particles. Since the targeted service temperature for the new steels is $650^{\circ} \mathrm{C}$, one set of creep testing was carried out on the material tempered at $650^{\circ} \mathrm{C}$. The other set of creep testing was carried out on materials tempered at $720^{\circ} \mathrm{C}$ for 6 hours. Although the as-quenched material showed better creep strength under the high load (120 MPa), after prolonged creep under the low load $(80 \mathrm{MPa})$ their creep strength converges. The creep rupture strength of the trial steel is better than P91 and close to P92, despite its much higher Cr content. 
Good creep resistance is only achieved if densely distributed fine precipitates, in this case Zphase, are quickly introduced into the steel. The finely dispersed precipitates can effectively retard dislocation migration in the ferrite matrix at high temperatures, thus leading to slower deformation or creep. Recent extensive work enables optimization of the alloy design of the new Z-phase strengthened steels. Z-phase precipitates are formed by direct $\mathrm{Cr}$ diffusion into the already existing MN precipitates [13], and the rate for their formation varies significantly, depending on the chemical composition of the steel and heat treatment. Thermodynamic modelling has shown that the $\mathrm{Cr}$ content in the steel is the main factor that controls the driving force for Z-phase formation [14]. When the Cr concentration increases from $9 \%$ to $12 \%$ the Z-phase formation rate can increase more than one order of magnitude $[10,15]$. Furthermore, the addition of Co is also, to certain extent, beneficial to enhance the phase transformation rate from MX to Z-phase [14]. In 9-12\% Cr steels three major types of Zphase precipitates can be formed based on their chemical composition: $\mathrm{CrVN}$ [16], $\mathrm{CrNbN}$ [7] and $\mathrm{CrTaN}$. The formation rate of $\mathrm{CrVN}$ is slow compared to that of $\mathrm{CrNbN}$ [17]. Although the crystal structure of Ta-containing Z-phase has been studied [18], to the authors' best knowledge, the formation rate of $\mathrm{CrTaN}$ in $9-12 \% \mathrm{Cr}$ steels has not been reported previously. In contrast to in $9 \% \mathrm{Cr}$ steels, where the Z-phase form fastest at $600^{\circ} \mathrm{C}$, in $12 \% \mathrm{Cr}$ steels $\mathrm{Z}$ phase precipitates form most rapidly at approximately $650^{\circ} \mathrm{C}[9,10]$. In fact, this is the target application temperature for this new generation of martensitic steels.

The trial steel exhibited a typical martensitic structure with precipitates and elongated laths (Figure 2). In the steel mainly two families of precipitates were formed, Z-phase and Laves phase $\left(\mathrm{Fe}_{2} \mathrm{~W}\right)$. A good indication of the precipitation reaction is provided by the accurate 
matrix composition obtained by APT. The precipitation of virtually the full volume fraction of Z-phase was rapid. Ta and $\mathrm{N}$, together with $\mathrm{B}$ and $\mathrm{C}$, were almost completely consumed out of the matrix after 24 hours at $650^{\circ} \mathrm{C}$, although the formed Z-phase are too small to be visible in the TEM high angle annular dark field (HAADF) micrograph (Figure 2 (a)). Then Z-phase precipitates coarsened slowly with time. After 10,000 hours fine (mostly $<100 \mathrm{~nm}$ ) Z-phase precipitates were still densely distributed in the steel (Figure 2 (b)). On the other hand, the precipitation of Laves phase was a prolonged process, which is indicated by the fact that the W concentration in the matrix decreased continuously from 24 hours to 10,000 hours. The measured concentration of $\mathrm{W}$ was 0.63 at.\% after 24 hours, 0.24 at.\% after 1005 hours and 0.20 at.\% after 10,000 hours. Laves phase precipitates were larger than Z-phase, and the first Laves phase precipitates were readily observed in the TEM after aging for 24 hours at $650^{\circ} \mathrm{C}$ (Figure 2 (a)), much larger $(\sim 500 \mathrm{~nm})$ but fewer Laves phase were observed after 10,000 hours at $650^{\circ} \mathrm{C}$ (Figure $2(\mathrm{~b})$ ). The large Laves phase precipitates are considered to be too big to contribute to creep resistance. However, W can contribute to solid solution strengthening, and small Laves phase formed in the early stages of creep can also contribute to precipitation strengthening.

Very dense and fine Z-phase precipitates were formed in the trial steel after aging for 24 hours. Figure 3 (a) shows a TaN-molecular ion map from an APT reconstruction, which illustrate typical Z-phase precipitates in the steel. Due to the differences in local magnification between the precipitates and the steel matrix, the chemical compositions of the precipitates is mixed by the steel matrix. However, since very little Fe exist in the precipitates, we can remove Fe and proportionally other matrix elements, such as $\mathrm{Cr}, \mathrm{Co}$ and $\mathrm{W}$. The obtained compositions, which would approximately reflect the actual chemical composition of the 
precipitates, were very close to the typical composition of Z-phase. Thus, the MX precipitates formed during tempering appeared to be already transformed into Z-phase after aging for 24 hours. The precipitates are 10-20 nanometres in size and in the form of thin blades. They were found in all the analysed APT specimens. However, their distribution was not homogeneous, which is normal for precipitates in $9-12 \% \mathrm{Cr}$ steels. The number density of Z-phase was calculated to be $9.6 \times 10^{22} \mathrm{~m}^{-3}$ based on results obtained from seven APT specimens. This figure is four orders of magnitude higher than that in a commercial $9 \% \mathrm{Cr}$ steel and higher than special thermomechanical treated $9 \% \mathrm{Cr}$ steels previously reported [19]. One reason for the high number density is that the precipitates are blade-shaped rather than spherical, which for a given volume fraction and diameter gives a much higher density. Another reason might be that for very small precipitates, APT gives accurate results on the volume and precipitate number without suffering from underestimation due to overlap of precipitates along the beam direction in a TEM. In this study, despite of their vast quantity, Z-phase precipitates were barely visible in the HAADF micrograph due to their extremely small size and blade-like morphology. On the other hand, as all high-resolution techniques, APT provides information from a rather limited analysis volume, typically several analyses each with a volume of $80 \times$ $80 \times 100 \mathrm{~nm}^{3}$

To ensure a long-term resistance against mechanical deformation, the dimension of the precipitates in the material should ideally be stable, or at least evolve slowly, i.e. the precipitate should coarsen slowly. The coarsening rate is described by the following equation [20]:

$$
K_{p}=\frac{8}{9} \frac{\gamma V_{m}^{\beta}}{\sum_{i=1}^{C} \frac{\left(x_{i}^{\beta}-x_{i}^{\alpha / \beta}\right)^{2}}{x_{i}^{\alpha / \beta} D_{i} / R T}}
$$


where $\gamma$ is the interfacial energy and $V_{m}^{\beta}$ is the molar volume of the precipitate phase, $D_{i}$ is the diffusion coefficient of element $i$ in the matrix, $x_{i}^{\beta}$ is the mole fraction of element $i$ in the precipitate and $x_{i}^{\alpha / \beta}$ is the mole fraction of element $i$ at the precipitate/matrix interface. The solubility of $\mathrm{Ta}$ in the ferrite matrix is virtually zero according to the APT results. The diffusion rate of Ta in ferrite is lower than that of $\mathrm{Cr}$ and $\mathrm{N}$ at $650^{\circ} \mathrm{C}$ [21]. Consequently, the Ta term will dominate the sum in the denominator in the equation for $K_{p}$ and determine the coarsening rate of Z-phase precipitates. In conventional steels the denominator is instead dominated by the $\mathrm{V}$ term.

The numerator in the expression for $K_{p}$ is proportional to the interfacial energy. The semicoherent interfacial energy that consists of elastic and chemical components was calculated for several (001)MN//(001)Fe, [100]MN//[110]Fe boundaries by a combination of a continuum description and density functional theory (DFT) [22]. The interfacial energy of TaN was found to be only slightly larger than that of $\mathrm{VN}, 0.6 \mathrm{~J} / \mathrm{m}^{2}$ and $0.5 \mathrm{~J} / \mathrm{m}^{2}$, respectively. Z-phase is expected to have the orientation relationship (001)CrTaN//(001)Fe, $[100] \mathrm{CrTaN} / /[100] \mathrm{Fe}$ with the matrix, and has a lattice parameter of only $\mathrm{a}=0.3004 \mathrm{~nm}[23]$ that actually gives a smaller misfit in the (001) plane than TaN/Fe, $4.8 \%$ vs $7.0 \%$. Although the chemical part of the interfacial energy might be somewhat larger for the Z-phase, the total semi-coherent interfacial energy should be similar to that of TaN. Summing the effects of interfacial energies, solubilities and diffusion rates in the matrix the coarsening rate for the Zphase should be of the same order as for VN in conventional steels. This is in accordance with the creep data obtained so far (Figure 1). 
The experimental results of precipitate microstructure show that the overall effect of the above aspects is actually a slow Z-phase coarsening rate. After 1005 hours of aging, the Zphase precipitates had coarsened to some extent, compared to after the 24-hour aging. The precipitates became thick disks in shape. Their typical size was 10-25 nm. In Figure 3 (b) TaN-molecular ion reconstruction map highlights the Z-phase precipitates. The number density of the precipitates was $\sim 2 \times 10^{22} \mathrm{~m}^{3}$, based on the APT results. Electron diffraction studies (e.g. Figure 3(c)) on Z-phase precipitates formed after 1005 hours aging showed that these precipitates have a more ordered tetragonal Z-phase crystal structure [16]. After prolonged exposure for 10,000 hours, these Ta-containing precipitates became clearly visible in the TEM/HAADF micrograph (Figure 3(d)). Many of them were still below $100 \mathrm{~nm}$, retaining the blade-like morphology, and mainly located along the lath boundaries. They are beneficial for retarding the deformation.

The chemical composition of Z-phase is shown in Table 2. For $\mathrm{CrTaN}$ the $\mathrm{Cr}$ and $\mathrm{Ta}$ ratio is rather high: $\mathrm{Cr}: \mathrm{Ta} \approx 1.2: 0.8$. This ratio matches very well with what was reported by Ettmayer, who managed to prepare tantalum Z-phase [23]. $\mathrm{The} \mathrm{Cr}_{1+\mathrm{x}} \mathrm{Ta}_{1-\mathrm{x}} \mathrm{N}$ precipitates also contain small amounts of $\mathrm{Fe}$ and $\mathrm{W}$, which are believed to be incorporated into the precipitates due to their relatively high content in the matrix. Although neither of them was intentionally added to the test steel, $\mathrm{V}$ and $\mathrm{Nb}$ were present in trace amounts and were incorporated into Z-phase, there reaching a concentration of $\sim 1$ at. $\%$.

The $\mathrm{C}$ and $\mathrm{B}$ levels in the Z-phase precipitates are also remarkably high, considering their extremely low amount in steels $(\sim 0.3$ at.\% in precipitates vs. 0.02 at.\% in the steel for C, and $\sim 0.1$ at. $\%$ in precipitates vs. 0.02 at. $\%$ in the steel for B). Figure 4 shows some interesting 
observations on the distribution of $\mathrm{C}$ and $\mathrm{B}$ in the Z-phase precipitates. C is distributed rather evenly in the $\mathrm{Cr}_{1+\mathrm{x}} \mathrm{Ta}_{1-\mathrm{x}} \mathrm{N}$ Z-phase, which means that $\mathrm{C}$ might have a certain solubility in Zphase. In contrast, B was only found at the interface between the Z-phase and the matrix, which means that the solubility of B in the Z-phase is limited. The B at the interfaces is believed to be beneficial, since it may decrease the interfacial energy of the precipitates, and thus retard the coarsening of the precipitates [24].

This study illustrates that instead of being detrimental thermodynamically stable Z-phase $\mathrm{CrTaN}$ can be used to strengthen high chromium containing 9-12\% $\mathrm{Cr}$ martensitic steel. More work, such as quantification of the coarsening rate of Z-phase and Laves phase precipitates and recovery of microstructure, is in progress. The new generation of steels have a great potential to be applied in future steam power plants with temperature up to $650^{\circ} \mathrm{C}$, providing good long-term creep and corrosion resistance and thermal efficiencies close to $50 \%$, and thus significantly reducing the carbon footprint of the power plants.

Financial support by the Swedish Energy Agency (contract number 31139-1), and Siemens Industrial Turbomachinery $\mathrm{AB}$ through the Swedish research program KME (contract numbers: 510 and 710), and the Research Foundation of VGB (contract number: 348) in Germany is gratefully acknowledged. The authors thank Dr Hilmar Danielsen for fruitful discussions.

\section{References}

[1] F. Masuyama, ISIJ Int. 41 (2001) 612.

[2] M. Taneike, F. Abe, K. Sawada, Natur. 424 (2003) 294.

[3] K. Maruyama, K. Sawada, J.-I. Koike, ISIJ Int. 41 (2001) 641.

[4] A.J. Sedriks, Chapter 10: Corrosion by hot gases and molten compounds, in: Corrosion of stainless steels, John Wiley \& Sons, 1996. 
[5] H. Nickel, Y. Wouters, M. Thiele, W.J. Quadakkers, Fresenius J. Anal. Chem. 361 (1998) 540.

[6] T. Uehara, A. Toji, S. Komatsubara, T. Fujita, in: J. Lecomte-Beckers, M. Carton, F. Schubert, P.J. Ennis (Eds.) Materials for advanced power engineering, Forschungszentrum Jülich GmbH, Liege, Belgium, 2002, pp. 1311-1320.

[7] A. Strang, V. Vodarek, Mater. Sci. Technol. 12 (1996) 552.

[8] M. Svoboda, J. Bursik, I. Podstranska, A. Krouppa, V. Sklenicka, K.H. Mayer, in: J. Lecomte-Beckers, M. Carton, F. Schubert, P.J. Ennis (Eds.) Materials for advanced power engineering, Forschungszentrum Jülich GmbH, Liege, Belgium, 2002, pp. 1521-1530.

[9] H.K. Danielsen, J. Hald, VGB PowerTech. 5 (2009) 68-73.

[10] H.K. Danielsen, P.E.d. Nunzio, J. Hald, Metall. Mater. Trans. A. 44 (2013) 2445.

[11] M.K. Miller, A. Cerezo, M.G. Hetherington, G.D.W. Smith, Specimen preparation, in: Atom probe field ion microscopy, Clarendon Press, Oxford, 1996, pp. 476-483.

[12] F. Liu, H.-O. Andrén, Ultramicosc. 111 (2011) 633-641.

[13] H.K. Danielsen, J. Hald, Mater. Sci. Eng. A. 505 (2009) 169.

[14] H.K. Danielsen, J. Hald, CALPHAD. 31 (2007) 505.

[15] K. Sawada, H. Kushima, K. Kimura, M. Tabuchi, ISIJ Int. 47 (2007) 733.

[16] H.K. Danielsen, J. Hald, F.B. Grumsen, M.A.J. Somers, Metall. Mater. Trans. A. 37A (2006) 2633.

[17] L. Cipolla, H.K. Danielsen, P.E. Di Nunzio, D. Venditti, J. Hald, M.A.J. Somers, Scripta Mater. 63 (2010) 324.

[18] H.K. Danielsen, J. Hald, Scripta Mater., 60 (2009) 811.

[19] R.L. Klueh, N. Hashimoto, P.J. Maziasz, Scripta Mater., 53 (2005) 275.

[20] J. Ågren, M.T. Clavaguera-Mora, J. Golcheski, G. Inden, H. Kumar, C. Sigli, CALPHAD, 24 (2000) 41.

[21] Q.A. Shaikh, Mater. Sci. and Technol. 6 (1990) 1177.

[22] D.H.R. Fors, G. Wahnström, J. Appl. Phys. 109 (2011) 113709.

[23] P. Ettmayer, Monatsh. Chem. 102 (1971) 858.

[24] F. Liu, D.H.R. Fors, A. Golpayegani, H.-O. Andrén, G. Wahnström, Metall. and Mater. Trans. A. 43 (2012) 4053. 
Figure 1. Creep rupture results at $650^{\circ} \mathrm{C}$ for the new $\mathrm{CrTaN}$-strengthened steel, either tempered at $650^{\circ} \mathrm{C}$ or at $720^{\circ} \mathrm{C}$, in comparison with two benchmark commercial steels, P91 and P92.

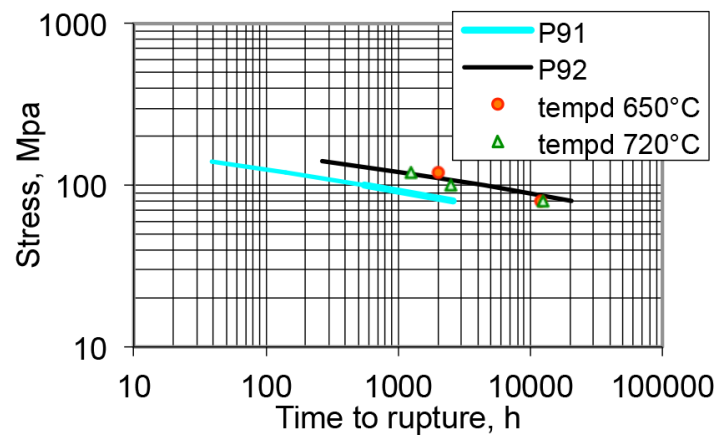

Figure 2. TEM/HAADF micrographs for samples aged at $650^{\circ} \mathrm{C}$ for different periods of time, showing evolution of microstructure in the CrTaN-strengthened steel. (a) Aged for 24 hours. Notice the laths and Laves phase precipitates (all particles with the bright contrast); Z-phase precipitates are not visible. (b) Aged for 10,000 hours. All the large bright particles are Laves phase (marked by arrows). The small bright particles are Z-phase, decorating the lath boundaries.

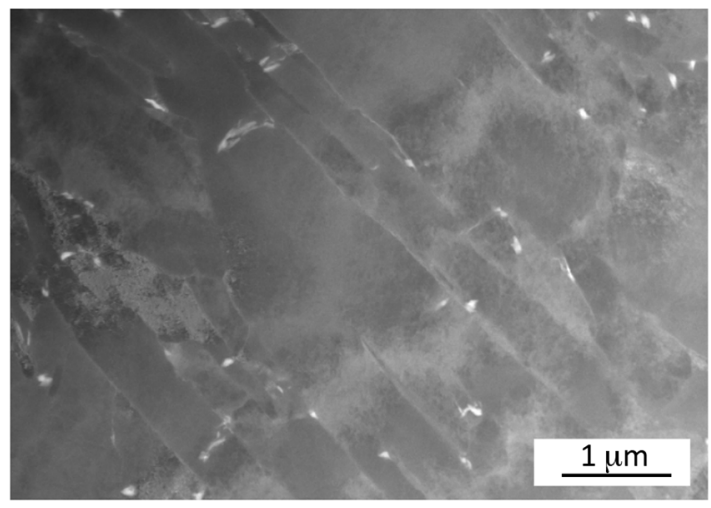

(a)

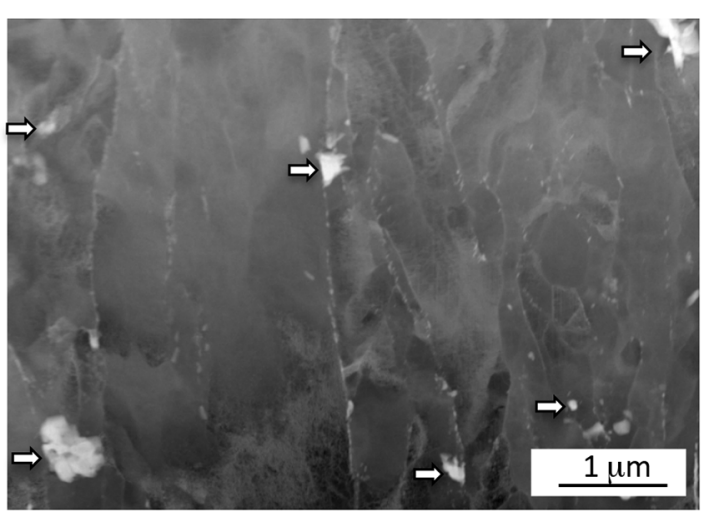

(b) 
Figure 3. Evolution of Z-phase precipitates. (a) Aged for 24 hours. APT reconstruction of TaN ion map. The box size $85 \times 85 \times 60 \mathrm{~nm}^{3}$. (b) Aged for 1005 hours. APT reconstruction of TaN ion map. The box size is $58 \times 58 \times 150 \mathrm{~nm}^{3}$. (c) Convergent beam electron diffraction pattern showing a Z-phase with a tetragonal [021] zone axis (from the sample aged for 1005 hours). (d) Aged for 10,000 hours. TEM/HAADF micrograph, showing Z-phase precipitates, most of which are smaller than $100 \mathrm{~nm}$.

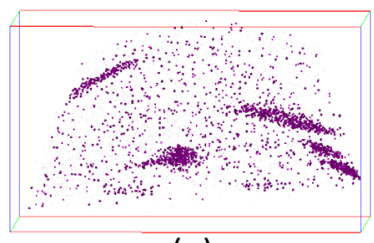

(a)

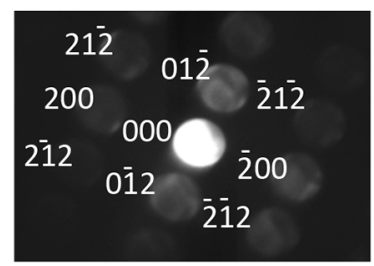

(c)

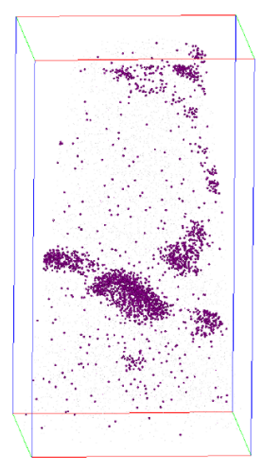

(b)

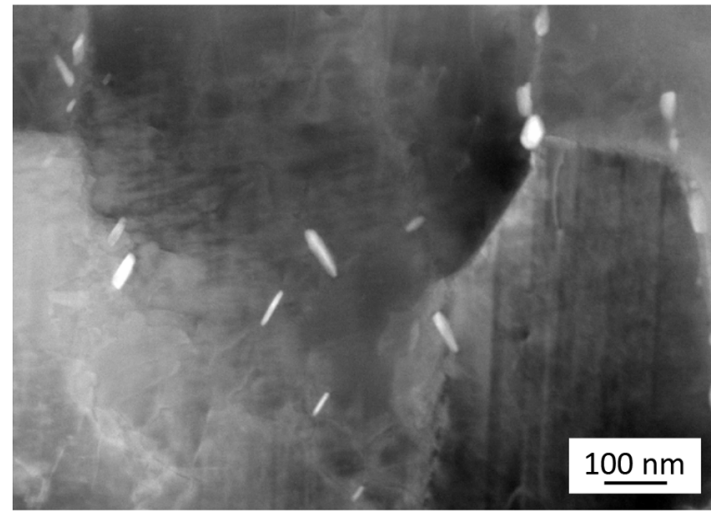

(d)

Figure 4. Proxigram analysis of an APT data set, showing quantitative boron and carbon concentration profiles across a Z-phase precipitate/matrix interface in the CrTaN-strengthened steel.

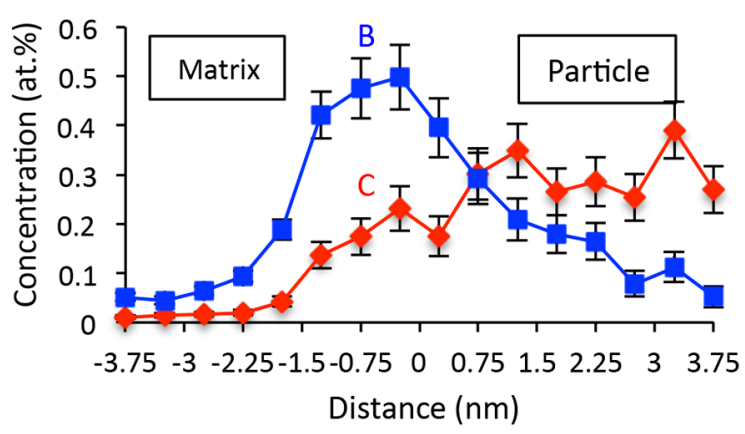


Table 1. Chemical composition of the test Z-phase strengthened steels in both weight and atomic

\begin{tabular}{lllllllllll}
\hline & Ni & Co & Cr & W & Ta & C & B & N & Si & Mn \\
\hline wt.\% & 0.50 & 7.30 & 11.79 & 2.90 & 0.39 & 0.005 & 0.004 & 0.033 & 0.30 & 0.48 \\
\hline at.\% & 0.48 & 7.01 & 12.84 & 0.89 & 0.12 & 0.02 & 0.02 & 0.13 & 0.60 & 0.49 \\
\hline
\end{tabular}

(Fe in balance). 